\title{
Endocannabinoid system and cannabinoids in neurogenesis - new opportunities for neurological treatment? Reports from experimental studies
}

\author{
Aleksandra Drab', Mirosław Zagaja', Agnieszka Haratym-Maj², Jarogniew Jacek Łuszczki ${ }^{1,3}$, \\ Marta Andres-Mach ${ }^{1}$ \\ ${ }^{1}$ Isobolographic Analysis Laboratory, Institute of Rural Health, Lublin, Poland \\ ${ }^{2}$ Department of Physiopathology, Institute of Rural Health, Lublin, Poland \\ ${ }^{3}$ Department of Patophysiology, Medical University, Lublin, Poland
}

Drab A, Zagaja M, Haratym-Maj A, Łuszczki JJ, Andres-Mach M. Endocannabinoid system and cannabinoids in neurogenesis - new opportunities for neurological treatment? Reports from experimental studies. J Pre-Clin Clin Res. 2017; 11(1): 76-80. doi: 10.26444/jpccr/74636

\begin{abstract}
Neurogenesis is one of the most important phenomenona affecting human life. This process consists of proliferation, migration and differentiation of neuroblasts and synaptic integrations of newborn neurons. Proliferation of new cells continues into old age, also in humans, although the most extensive process of cell formation occurs during the prenatal period. It is possible to distinguish two regions in the brain responsible for neurogenesis: the dentate gyrus (DG) of the hippocampus and the sub-ventricular zone (SVZ). Hippocampal neurogenesis is very sensitive to various physiological and pathological stimuli. The functional integration of the newly-born dentate granule cells into hippocampal circuitry, and their ability to mediate long-term potentiation in DG, has led to the hypothesis that neurogenesis in the adult brain may play a key role in learning and memory function, as well as cognitive dysfunction in some diseases. Brain disorders, such as neurodegenerative diseases or traumatic brain injuries, significantly affect migration, proliferation and differentiation of neural cells. In searching for the best neurological drugs protecting neuronal cells, stimulating neurogenesis, while also developing no side-effects, endocannabinoids proved to be a strong group of substances having many beneficial properties. Therefore, the latest data is reviewed of the various experimental studies concerning the analysis of the most commonly studied cannabinoids and their impact on neurogenesis.
\end{abstract}

Key words

neurogenesis, cannabinoids, endocannabinoid system

\section{INTRODUCTION}

Effective brain development depends on the coordination of proper proliferation, migration and differentiation of new-born neuronal cells. Among the variety of mechanisms involved in the regulation of neural development, there can be distinguished G-protein-coupled receptors, involved in signal transduction [1], neurotransmitters like gammaaminobutyric acid (GABA) and glutamic acid (Glu) actively involved in instructing neural progenitor (NP) cell proliferation [2]. Additionally, the endocannabinoid system (eCB) is expressed since early stages of neural tissue formation [3]. The involvement of the eCB system in the regulation of neural plasticity is mainly based on its neuromodulatory function as an endocannabinoid receptor 1 (CB1) showing a wide regulatory role in most types of synapses [4]. Many pharmacological studies have evidenced that endocannabinoids (eCBs) and drugs targeting the eCB system (synthetic agonists and antagonists, plant derived) can affect neuronal development and specification [5]. This review presents an overview of the newest scientific reports on the effects of eCB system, as well as endogenous and

Address for correspondence: Marta Andres-Mach, Isobolographic Analysis Laboratory, Institute of Rural Health, Jaczewskiego 2, Lublin, Poland

E-mail: mandres@wp.pl

Received: 16 May 2017; accepted: 8 June 2017 exogenous cannabinoids, on the process of neurogenesis from various animal studies.

Endocannabinoid system and endocannabinoids. $\mathrm{eCB}$ is a complex of metabolic enzymes, endocannabinoids, and receptors detecting their presence and initiating a cascade of chemical responses. Cannabinoid signaling was shown to be involved in neurogenic processes (neuronal proliferation, specification, and maturation) and in the maintenance and survival of differentiated neural cells $[4,5]$.

$\mathrm{eCB}$ is composed of two 7-transmembrane-domain and $\mathrm{G}$ protein-coupled receptors (GPCRs) for THC CB1 receptor and $\mathrm{CB} 2$ receptor and their 2 endocannabinoid signaling molecules, anandamide (AEA) and 2-arachidonoylglycerol (2-AG, Fig. 1) [6, 7].

Both humans and animals produce the AEA and 2-AG compounds, which help to regulate many biological functions. AEA and 2-arachidonoylglycerol are known to regulate human cardiovascular functions and homeostasis [8]. AEA has been shown to control the cell choice between growth and death, and 2-AG was shown to be a direct substrate of the cyclooxygenase COX and lipoxygenase LOX pathway [9]. Moreover 2-AG and AEA are endocannabinoids that have been implicated in many physiologic disorders, including obesity, metabolic syndromes, hepatic diseases, pain, neurologic disorders, and inflammation [10]. 


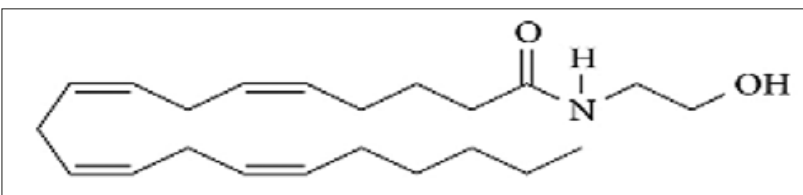

Arachidonoyl ethanolamide (AEA)

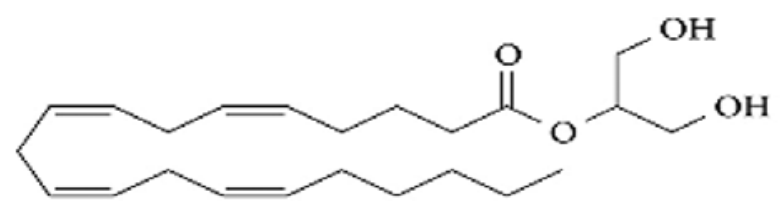

2-Arachidonoyl glycerol (2-AG)

Figure 1. Chemical structures of the endocannabinoids AEA and 2-AG

The endogenous cannabinoid ligands (anandamide, $\mathrm{N}$-arachidonoyl ethanolamide and 2-arachidonoyglycerol) are substances synthesized from lipid precursors in the neuronal membrane. AEA and 2-AG are synthesized 'on demand', not stored in the cell, and are degraded quickly [11]. Synthesis of both of the endocannabinoids is mainly dependent on intracellular $\mathrm{Ca} 2+$ concentrations. The primary pathway through which AEA is synthesized involves the $\mathrm{Ca} 2+$-dependent cleavage of its membrane precursor $\mathrm{N}$-arachidonyl phosphatidylethanolamine by phospholipase D [12], whereas diacylglycerol lipase- $\alpha$ (DGL $\alpha$ ) and diacylglycerol lipase- $\beta$ (DGL $\beta$ ) are mainly responsible for the synthesis of 2-AG [13]. The main metabolizing enzymes of anandamide and 2-arachidonoylglycerol are fatty acid amide hydrolase (FAAH) and monoacylglycerol lipase (MAGL), which act upon AEA and 2-AG respectively [14 15]. Both $\mathrm{AEA}$ and 2-AG bind to the $\mathrm{CB} 1$ and $\mathrm{CB} 2$ receptors; however, AEA has a higher affinity to the $\mathrm{CB} 1$ receptor, whereas 2-AG favours the CB2 receptor [16]. Manipulations of endocannabinoid degradative enzymes, $\mathrm{CB}_{1}$ and $\mathrm{CB}_{2}$ receptors, and their endogenous ligands have been shown to play an important role in modulating cellular and molecular changes in traumatic brain injury (TBI) including: cell death, excitotoxicity, neuroinflammation or cerebrovascular breakdown [17].

CB1 and CB2 receptors have also been associated with postnatal oligodendrogenesis. Increase in the number of glial precursors in the subventricular zone of postnatal rats is caused by activation of $\mathrm{CB} 1$ receptor, whereas activation of the CB2 receptor increases polysialylated neural cell adhesion molecule expression, which is necessary for the migration of oligodendrocyte precursors [15 18]. CB receptor activation is associated primarily with regulation of ion channels through inhibition of $\mathrm{Ca}^{2+}$ channels and activation of $\mathrm{K}^{+}$channels $[19,20]$. These receptors inhibit adenylate cyclase and the formation of cyclic AMP [21]. In addition, cannabinoids activate different protein kinase cascades (e.g., the mitogen-activated protein kinases MAPK and the phosphatidylinositol 3-kinase/Akt). The endocannabinoid system plays an important role in controlling neural cell fate. On the one hand, it can exert a pro-survival action of different neural cell types [22], but if transformed cells are found they are directed to apoptosis by cannabinoid treatment and therefore the system exerts an antitumoral action against different types of cancer [23].

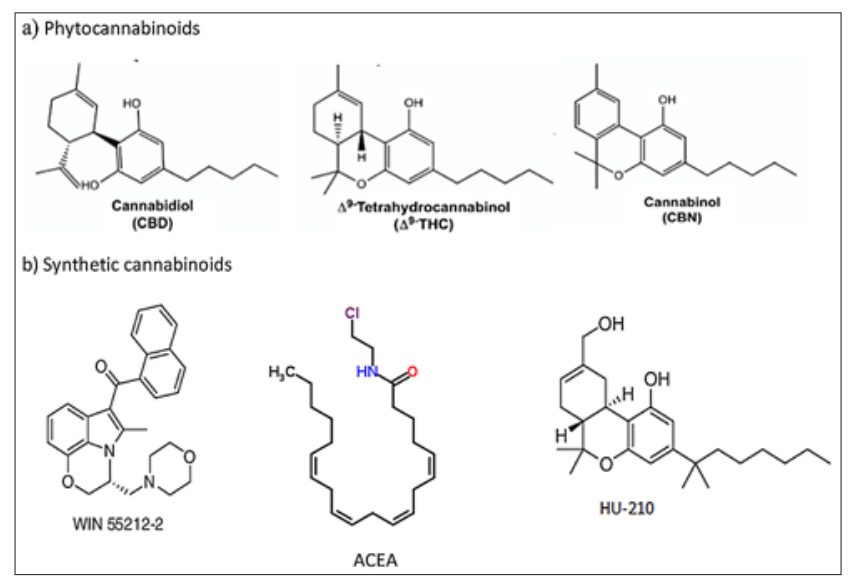

Figure 2. Chemical structures of the exogenous cannabinoids

Exogenous cannabinoids. The term 'cannabinoids' designates a family of compounds with activity upon cannabinoid receptors and encompasses all substances structurally related to cannabis. Exogenous cannabinoids were first extracted from the plant Cannabis sativa. and they belong to the group of phytocannabinoids.

Into a class of Cannabis plant-derived cannabinoids fall: cannabinol, cannabidiol (CBD) and $\Delta 9$-tetrahydrocannabinol ( $\Delta 9$-THC, Fig. 2a). Most of the psychoactive effects of cannabis are mediated by $\Delta 9$-THC [24]. The second group of exogenous cannabinoids is manufactured by chemicallysynthetic cannabinoids, such as HU-210, WIN55,212-2 mesylate or arachidonyl-2'-chloroethylamide ACEA (Fig. 2b).

All types of cannabinoids are known to act through two cannabinoid receptors, $\mathrm{CB}_{1}$ and $\mathrm{CB}_{2}[6,21]$. As mentioned above, the major cannabinoid receptor in the central nervous system is cannabinoid receptor 1 (CB1), first described and cloned in the early 1990s [25]. CB1 receptors are highly expressed in regions of the brain which are responsible for movement, memory processing and pain modulation [26]. A second cannabinoid receptor, the $\mathrm{CB}_{2}$ receptor, was also cloned in the 1990s [27]. $\mathrm{CB}_{2}$ receptors are found mainly in cells and tissues of the immune system, but are also present in the brain [28].

Marijuana, through its ability to regulate the endocannabinoid system, has anticonvulsant, antipsychotic, antidepressant and anxiolytic properties [29,30]. The authors of the presented review distinguish several important mechanisms of action of cannabinoids, one of which is the ability to promote neuronal plasticity [31]. Additionally, by inhibiting calcium and potassium channels activation, cannabinoids are able to alter brain activity [32]. They are also involved in the control of glutamate-induced excitotoxicity [33]. Another important mechanism of action of cannabinoids has been its regulatory role of adult hippocampal neurogenesis.

Neurogenesis. Neurogenesis is the process of creating new neurons in the brain from precursors. For many years, the belief was prevalent that neurogenesis occurs only during the embryonic and perinatal stages in mammals [34]. In 1965 , Altman's pioneering studies provided evidence for the formation of new neurons in adult rats [35]. These studies used a technique that labeled dividing cells with $[3 \mathrm{H}]$ thymidine, which incorporates into the replicating DNA [36]. This initiated intensive studies on adult neurogenesis. 
Adult neurogenesis occurs continuously in the subventricular zone (SVZ) of the rostral lateral ventricles, as well as the subgranular zone of the dentate gyrus (DG) of the hippocampus. This usually includes four key stages. In the first stage, the quiescent neural stem cells (nsCs) start to proliferate to generate the transit amplifying cells (TACs). The TACs then undergo fate specification and give rise to the neuroblasts. Depending on where newly-generated cells originate, they migrate to different places. Neuroblasts from the SVZ get into the main olfactory bulb (MOB), andcells from the subgranular zone migrate within the DG. Most of these cells differentiate into neurons and integrate into the existing olfactory circuitry (cells derived from SVZ) and DG circuitry (cells from subgranular zone). Adult-generated DG neurons may play a role in spatial learning, long-term spatial memory retention, trace conditioning, and contextual fear conditioning. Neurons in the olfactory bulb likely play a role in short-term olfactory memory, olfactory fear-conditioning, and long-term associative olfactory memory $[37,38]$. There is also evidence suggesting that adult neurogenesis occurs in other neurogenic regions of the brain and, in particular, in the neocortex [39, 40, 41], piriform cortex [40], and striatum [42].

Neurogenesis and cannabinoids. Adult neurogenesis has been shown to be a good example of brain plasticity modulated by the endocannabinoid system. In recent years, several studies have provided evidence that the endocannabinoid system is being expressed on neural stem cells. It was shown that the downstream activation of $\mathrm{CB}_{1}$ and $\mathrm{CB}_{2}$ cannabinoid receptors, as well as the enzymes responsible for the synthesis of the endocannabinoid 2-AG, diacylglycerol lipase a (DAGL $\alpha$ ) and DAGL $\beta$, and degradation, monoacylglycerol lipase (MAGL), can modulate neurogenesis by a number of neuroimmune molecules (cytokines) in glial cells, neurons and NSCs [43]. Plant-derived extracts of cannabinoids, such as $\Delta$-tetrahydrocannabinol (THC) and cannabidiol (CBD), were studied in female C57Bl/6 and Nestin-GFP-reporter mice in order to assess their effects on the proliferation and maturation of neuronal progenitor cells, together with spatial learning performance [44]. Obtained results indicate that THC and CBD differed in their effects on spatial learning and adult neurogenesis. CBD did not impair learning but increased adult neurogenesis, whereas THC reduced learning capability without affecting adult neurogenesis. Moreover, CBD exerts therapeutically promising effects on human mental health, such as inhibition of psychosis, anxiety and depression. The anxiolytic effect of cannabidiol on chronically-stressed mice depends on hippocampal neurogenesis and is an outcome of the proneurogenic action of CBD which, in turn. facilitates endocannabinoidmediated signaling [45]. Abboussi et al. [46] investigated the behavioural neurogenic effects of chronic exposure to the endocannabinoid agonist WIN55,212-2 during adolescence, by evaluating emotional and cognitive performances, and the consequences on neurogenesis along the dorso-ventral axis of the hippocampus in adult rats. Obtained results suggest that long-term exposure to WIN55,212-2 may affect more potently spatial learning and memory in adolescents, compared to adult rats, via a negative action on hippocampal plasticity. In subsequent studies, Compagnucci et al. [47] investigated the role of endocannabinoids as modulators of neuronal functions, including neurogenesis. Obtained results showed that the Type-1 $\left(\mathrm{CB}_{1}\right)$ cannabinoid receptor
Table 1. In vivo effects of cannabinoids on NCPs proliferation and neurogenesis - review of literature of the past few years

\begin{tabular}{lccc}
\hline Cannabinoid & Animal model & Results & Reference \\
\hline WIN55,212-2 & F-344 rats & Increase & {$[50]$} \\
\hline - CBD & $\begin{array}{c}\text { C57BI/6 and Nestin- } \\
\text { GFP-reporter mice }\end{array}$ & $\begin{array}{c}\text {-decreased neurogenesis } \\
- \text { THC }\end{array}$ & {$[40]$} \\
\hline HU-308 & $\begin{array}{c}\text { CB } \text { receptor knock- } \\
\text { out mice }\end{array}$ & $\begin{array}{c}\text { Increased NCPs proliferation } \\
\text { C57BI/6 mice }\end{array}$ & {$[47]$} \\
\hline -CBD & Wistar rats & Reduced neurogenesis & {$[42]$} \\
\hline WHC & GFAP/Gp120 Tg mice & Enhanced neurogenesis & {$[44]$} \\
\hline AM1241 & Sprague-Dawley rats & No changes in neurogenesis & {$[48]$} \\
\hline THC & & & {$[41]$} \\
\hline ACEA & C57Bl/6 mice & Increased neurogenesis & {$[51]$} \\
\hline WIN55,212-2 & C57BL/6 mice & Increased NCPs proliferation & {$[49]$} \\
\hline
\end{tabular}

favoured differentiation of neural progenitors into neurons and enhanced their maturation in a culture. This effect was accompanied by reduced activity of the extracellular signal-regulated protein kinases 1 and 2 (ERK1/2) pathway, and by changes in gene expression that support neuronal differentiation and morphological maturation. In other studies concerning the cannabinoid $\mathrm{CB}_{2}$ receptor agonist AM1241, it was found that AM1241 enhances neurogenesis in GFAP/ Gp120 transgenic mice displaying deficits in neurogenesis [48]. Jin et al. [49] showed that $\mathrm{CB}_{1}$ receptor regulates adult neurogenesis in vivo, as measured by the increased level of BrdU cells positive cells located in neuroproliferative zones of the brain and that express neuronal lineage marker proteins. Moreover, neurogenesis is impaired in mice lacking $\mathrm{CB1R}$, implying that endogenous signaling through this receptor promotes basal levels of neurogenesis in vivo. The $\mathrm{CB}_{2}$ receptor agonist rescued impaired neurogenesis caused by HIV-1/Gp120 insult. Thus, $\mathrm{CB}_{2}$ receptor agonists may act as neuroprotective agents, restoring impaired neurogenesis in patients with HAD. While GFAP/Gp120 Tg mice exhibited impaired neurogenesis and a decrease in cells with proliferating cell nuclear antigen (PCNA), administration of AM1241 to GFAP/Gp120 Tg mice resulted in enhanced in vivo neurogenesis in the hippocampus. An endogenous metabolite of docosahexaenoic acid and its derivatives ( $\mathrm{N}$-docosahexaenoylethanolamine and $\mathrm{N}$-docosahexaenoylethanolamide) were shown to stimulate neurite growth, synaptogenesis, glutamatergic synaptic activity and neuronal differentiation of neural cells in hippocampal neurons $[50,51]$. Results of subsequent studies also confirmed the influence of the endocannabinoid system on neural progenitor cells (NCPs) regulation. CB2 cannabinoid receptors were found to promote neural progenitor cell proliferation via the mammalian target of rapamycin complex $1 \mathrm{mTORC1}$ signaling in vitro in hippocampal HiB5 progenitor cell line, NP-derived neurosphere cultures, organotypic embryonic cortical cultures, but also in vivo on hippocampal adult neurogenesis experiments, providing a mechanism of action and a rationale for the use of nonpsychotomimetic $\mathrm{CB}(2)$ receptor-selective ligands as a novel strategy for the control of NP cell proliferation and neurogenesis [52]. Results obtained by Steel et al. [53] using a spatial training protocol indicated that THC-treatment had no effect on reduced hippocampal proliferation, and increased survival 
of new-born hippocampal cells by training. Hutch and Hegg [54] indicated that cannabinoids WIN 55,212-2 or 2-arachidonylglycerol induce proliferation, but do not induce neurogenesis nor non-neuronal cell generation in the mouse olfactory epithelium. On the other hand, it was reported that neurogenesis in aged rats can be significantly increased by a low, continuous, non-psychoactive dose of a cannabinoid receptor agonist, WIN-55,212-2 [55]. In the current study, the last investigations by the authors using ACEA, showed stimulation of neurogenesis in mice treated with valproic acid (VPA), whereas long term administration of VPA itself slightly decreased the amount of newly-born neurons in the mouse dentate subgranular zone, when compared to the control group [56]. Similar results were obtained in a mouse pilocarpine model of epilepsy [57]. The differences in the amount of newborn cells in the dentate gyrus between control healthy and ACEA+VPA treated mice are displayed in Fig. 3.

\section{CONCLUSIONS}

Every day, new information is being discovered from the world of science on the uniqueness and the potential of the human brain. This uniqueness is even greater when dealing with brain disorders. The endocannabinoid system is emerging as a key regulator of many neuronal systems relevant to neurodegenerative disorders. Scientists are constantly looking for drugs which have strong neuroprotective properties and no side-effects. Thus, the problem concerning the effect of cannabinoids as potential neuroprotective substances in the process of neurogenesis in various degenerative disorders is very interesting, and certainly requires more advanced and intensive research.

\section{Acknowledgments}

The study was supported by a grant from the National Science Centre (Grant No.: UMO2012/05/B/NZ7/02459, Krakow, Poland).

\section{REFERENCES}

1. Dorsam RT, Gutkind JS. G-protein-coupled receptors and cancer. Nat Rev Cancer 2007; 7:79-94

2. Haydar TF, Wang F, Schwartz ML, Rakic P. Differential modulation of proliferation in the neocortical ventricular and subventricular zones. J Neurosci 2000; 20:5764-5774

3. Harkany T, Guzman M, Galve-Roperh I, Berghuis P, Devi LA, Mackie $\mathrm{K}$. The emerging functions of endocannabinoid signaling during CNS development. Trends Pharmacol Sci 2007; 28:83-92

4. Katona I, Freund TF. Endocannabinoid signaling as a synaptic circuit breaker in neurological disease. Nat Med 2008; 14:923-930

5. Galve-Roperh I, Aguado T, Palazuelos J, Guzman M. Mechanisms of control of neuron survival by the endocannabinoid system. Curr Pharm Des 2008; 14:2279-2288

6. Piomelli D, The molecular logic of endocannabinoid signalling. Nat Rev Neurosci 2003; 4(11):873-84

7. Watkins BA, Kim J. The endocannabinoid system: directingeating behavior and macronutrient metabolism. Front Psychol 2015; 5: 1506.

8. Pacher P, Steffens S. The emerging role of the endocannabinoid system in cardiovascular disease. Semin. Immunopathol. 2009 31:63-77.

9. Chen JK, Chen J, Imig JD, Wei S, Hachey DL, Guthi JS, Falck JR, Capdevila $\mathrm{JH}$, Harris RC. Identification of novel endogenous cytochrome p450 arachidonate metabolites with high affinity for cannabinoid receptors. J Biol Chem. 2008 283:24514-24524.

10. Turcotte C, Chouinard F, Lefebvre JS, Flamand N. Regulation of inflammation by cannabinoids, the endocannabinoids 2 -arachidonoylglycerol and arachidonoyl-ethanolamide, and their metabolites. J Leukoc Biol. 2015 Jun;97(6):1049-70.

11. Di Marzo V, Bifulco M, De Petrocellis L: The endocannabinoid system and its therapeutic exploitation. Nat Rev Drug Discov 2004; 3:771-784

12. Di Marzo V, Fontana A, Cadas H, Schinelli S, Cimino G, Schwartz JC, et al. Formation and inactivation of endogenous cannabinoid anandamide in central neurons. Nature 1994; 372(6507):686-91.

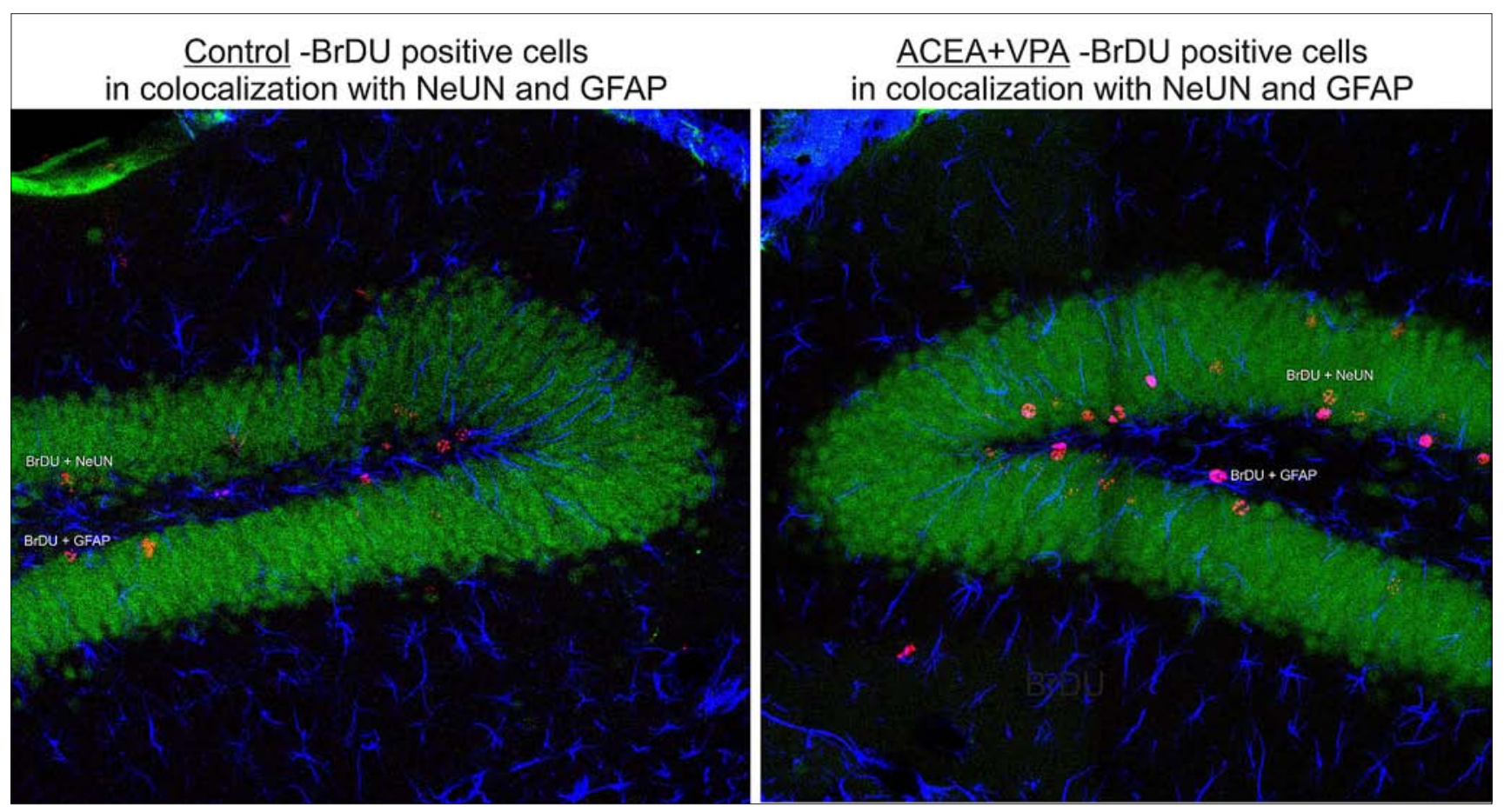

Figure 3. BrDU positive cells in colocalization with NeuN and GFAP in control healthy and VPA+ACEA treated mice

The number of BrdU positive cells displaying astrocyte-specific (GFAP), neuron-specific (NeuN), bromodeoxyuridine (BrDU)- specific markers was determined using confocal microscopy to score the colocalization of BrdU and phenotypic indicators. 
13. Bisogno T, Howell F, Williams G, Minassi A, Cascio MG, Ligresti A, et al. Cloning of the first sn1-DAG lipases points to the spatial and temporal regulation of endocannabinoid signaling in the brain. J Cell Biol. 2003;163(3):463-8.

14. Cravatt BF, Giang DK, Mayfield SP, Boger DL, Lerner RA, Gilula NB. Molecular characterization of an enzyme that degrades neuromodulatory fatty-acid amides. Nature 1996;384(6604):83-7.

15. Petrosino S, Di Marzo V: FAAH and MAGL inhibitors: therapeutic opportunities from regulating endocannabinoid levels. Curr Opin Investig Drugs 2010; 11:51-62

16. Pacher P, Batkai S, Kunos G. The endocannabinoid system as an emerging target of pharmacotherapy. Pharmacol Rev. 2006;58(3):389-462.

17. Schurman LD, Lichtman AH. Endocannabinoids: A Promising Impact for Traumatic Brain Injury. Front Pharmacol. 2017; Feb 17;8:69.

18. Arévalo-Martín A, García-Ovejero D, Rubio-Araiz A, Gómez O, Molina-Holgado F, Molina-Holgado E. Cannabinoids modulate Olig2 and polysialylated neural cell adhesion molecule expression in the subventricular zone of post-natal rats through cannabinoid receptor 1 and cannabinoid receptor 2. Eur J Neurosci. 2007;26(6):1548-59.

19. Mackie K, Devane WA, Hille B. Anandamide, an endogenous cannabinoid, inhibits calcium currents as a partial agonist in N18 neuroblastoma cells. Mol Pharmacol. 1993;44(3):498-503.

20. Hampson RE, Mu J, Deadwyler SA. Cannabinoid and kappa opioid receptors reduce potassium K current via activation of $\mathrm{G}(\mathrm{s})$ proteins in cultured hippocampal neurons. J Neurophysiol. 2000;84(5):2356-64.

21. Howlett, A.C., Barth, F., Bonner, T.I. Et al. International Union of Pharmacology. XXVII. Classification of cannabinoid receptors. Pharmacol Rev 2002, 54(2): 161-202

22. Mechoulam R, Spatz M, Shohami E. Endocannabinoids and neuroprotection. Sci STKE. 2002; 23;2002(129):re5.

23. Guzmán M. Cannabinoids: potential anticancer agents. Nat Rev Cancer. 2003 Oct;3(10):745-55.

24. Friedman D, Devinsky O. Cannabinoids in the Treatment of Epilepsy. N Engl J Med. 2015 Sep 10;373(11):1048-58.

25. Matsuda LA, et al. Structure of a cannabinoid receptor and functional expression of the cloned cDNA. Nature 1990;346:561-564

26. Baker D, Pryce G, Davies WL, Hiley CR. In silico patent searching reveals a new cannabinoid receptor. Trends Pharmacol Sci 2006;27(1):1-4.

27. Munro S, Thomas KL, Abu-Shaar M. Molecular characterization of a peripheral receptor for cannabinoids. Nature. 1993 Sep 2;365(6441):61-5.

28. Onaivi, E.S. Neuropsychobiological evidence for the functional presence and expression of cannabinoid CB2 receptors in the brain. Neuropsychobiology, 2006; 54(4), 231-246.

29. Moreira, F.A.; Aguiar, D.C.; Guimarães, F.S. Anxiolytic-like effect of cannabidiol in the rat Vogel conflict test. Prog. Neuropsychopharmacol. Biol. Psychiatry, 2006; 30(8), 1466-71.

30. Bergamaschi, M.M.; Queiroz, R.H.; Chagas, M.H.;de Oliveira D.C.; De Martinis, B.S.; Kapczinski, F.; et al. Cannabidiol reduces the anxiety induced by simulated public speaking in treatment-naïve social phobia patients. Neuropsychopharmacology, 2011;36, 1219-26.

31.Zoppi S, Pérez Nievas BG, Madrigal JL, Anzanares J, Eza JC, GarcíaBueno B. Regulatory role of cannabinoid receptor 1 in stress-induced excitotoxicity and neuroinflammation. Neuropsychopharmacology. 2011;36(4):805-18.

32. Szabo, B, Schlicker, E. Effects of cannabinoids on neurotransmission. Handb. Exp. Pharmacol., 2005; 168, 327-165.

33. Marsicano G, Goodenough S, Monory K, Hermann H, Eder M, Cannich A, et al. CB1 cannabinoid receptors and on-demand defense against excitotoxicity. Science. 2003;302(5642):84-8.

34. Ming GL, Song H. Adult neurogenesis in the mammalian central nervous system. Annu Rev Neurosci. 2005;28:223-50.

35. Altman J, Das GD. Autoradiographic and histological evidence of postnatal hippocampal neurogenesis in rats. J Comp Neurol. 1965 Jun;124(3):319-35.

36. Altman J, Das GD. Postnatal neurogenesis in the guinea-pig. Nature 1967 Jun 10;214(5093):1098-101.

37. Christie B. R., Cameron H. A. Neurogenesis in the adult hippocampus. Hippocampus 2006 16, 199-207
38. Ming GL, Song H. Adult neurogenesis in the mammalian brain: significant answers and significant questions. Neuron. 2011 May $26 ; 70(4): 687-702$.

39. Altman J. Are new neurons formed in the brains of adult mammals? Science. 1962 Mar 30;135(3509):1127-8

40. Bernier P. J., Bedard A., Vinet J., Levesque M., Parent A. Newly generated neurons in the amygdala and adjoining cortex of adult primates. Proc. Natl. Acad. Sci. U.S.A 2002. 99, 11464-11469

41. Cameron HA, Dayer AG. New interneurons in the adult neocortex: small, sparse, but significant? Biol Psychiatry. 2008 Apr 1;63(7):650-5

42. Bédard A, Lévesque M, Bernier PJ, Parent A. The rostral migratory stream in adult squirrel monkeys: contribution of new neurons to the olfactory tubercle and involvement of the antiapoptotic protein $\mathrm{Bcl}-2$. Eur J Neurosci. 2002; (10):1917-24.

43. Wolf SA, Bick-Sander A, Fabel K, Leal-Galicia P, Tauber S, RamirezRodriguez G, et al. Cannabinoid receptor CB1 mediates baseline and activity-induced survival of new neurons in adult hippocampal neurogenesis. Cell Commun Signal. 2010 17;8:12.

44. Molina-Holgado E., Molina-Holgado F. Mending the broken brain: neuroimmune interactions in neurogenesis. J Neurochem. 2010114:1277-1290.

45. Campos AC, Ortega Z, Palazuelos J, Fogaça MV, Aguiar DC, DíazAlonso J, et al. The anxiolytic effect of cannabidiol on chronically stressed mice depends on hippocampal neurogenesis: involvement of the endocannabinoid system. Int J Neuropsychopharmacol. 2013 Jul;16(6):1407-19.

46. Abboussi O. Chronic exposure to WIN55,212-2 affects more potently spatial learning and memory in adolescents than in adult rats via a negative action on dorsal hippocampal neurogenesis. Pharmacol Biochem Behav. 2014 120:95-102.

47. Compagnucci C, Di Siena S, Bustamante MB, Di Giacomo D, Di Tommaso M, Maccarrone M, et al. Type-1 (CB1) cannabinoid receptor promotes neuronal differentiation and maturation of neural stem cells. PLoS One. 2013;8(1):e54271.

48. Avraham HK, Jiang S, Fu Y, Rockenstein E, Makriyannis A, Zvonok $A$, et al. The cannabinoid $\mathrm{CB}_{2}$ receptor agonist AM1241 enhances neurogenesis in GFAP/Gp120 transgenic mice displaying deficits in neurogenesis. Br J Pharmacol. 2014; 171(2):468-79.

49. Kim HY, Moon HS, Cao D, Lee J, Kevala K, Jun SB, et al. $\mathrm{N}$-Docosahexaenoylethanolamide promotes development of hippocampal neurons. Biochem J. 2011 15;435(2):327-36.

50. Jin K, Xie L, Kim SH, Parmentier-Batteur S, Sun Y, Mao XO, Childs J, Greenberg DA. Defective adult neurogenesis in CB1 cannabinoid receptor knockout mice. Mol Pharmacol. 2004 66(2):204-8.

51. Rashid MA, Katakura M, Kharebava G, Kevala K, Kim HY. $\mathrm{N}$-Docosahexaenoylethanolamine is a potent neurogenic factor for neural stem cell differentiation. J Neurochem. 2013 Jun;125(6):869-84.

52. Palazuelos J, Ortega Z, Díaz-Alonso J, Guzmán M, Galve-Roperh I. CB2 cannabinoid receptors promote neural progenitor cell proliferation via mTORC1 signaling. J Biol Chem. 2012 6;287(2):1198-209.

53. Steel RW, Miller JH, Sim DA, Day DJ. Delta-9-tetrahydrocannabinol disrupts hippocampal neuroplasticity and neurogenesis in trained, but not untrained adolescent Sprague-Dawley rats. Brain Res. 2014 Feb 22;1548:12-9.

54. Hutch CR, Hegg CC. Cannabinoid receptor signaling induces proliferation but not neurogenesis in the mouse olfactory epithelium. Neurogenesis (Austin). 2016 Jan 13;3(1)

55. Marchalant, Y; Brothers, HM; Wenk, GL. Cannabinoid agonist WIN$55,212-2$ partially restores neurogenesis in the aged rat brain. Mol. Psychiatry, 2009, 14(12), 1068-9.

56. Andres-Mach M, Haratym-Maj A, Zagaja M, Rola R, Maj M, Chrościńska-Krawczyk M, et al. ACEA (a highly selective cannabinoid CB1 receptor agonist) stimulates hippocampal neurogenesis in mice treated with antiepileptic drugs. Brain Res. 2015 Oct 22;1624:86-94.

57. Andres-Mach M, Zagaja M, Haratym-Maj A, Rola R, Maj M, Haratym J, et al. A Long-Term Treatment with Arachidonyl-2'-Chloroethylamide Combined with Valproate Increases Neurogenesis in a Mouse Pilocarpine Model of Epilepsy. Int J Mol Sci. 2017; 25;18(5). 